\title{
Nurse's Experience Program In Implementing Intravenal Chemotherapy Treatment In Cancer Patients: A Phenomenology Study
}

\author{
Eben Haezar Kristian*, Florensius Andri, Christianus Eko Purwanto Widoroni \\ Nursing Academy of Dharma Insan, Pontianak, Indonesia \\ Corresponding author: ebenhaezar02@gmail.com
}

\begin{abstract}
Background: Cancer or malignant tumor is uncontrolled growth of cells or tissue and spreads from abnormal cells, if the spread is uncontrolled it can cause death. Experience is a very dynamic, complex and subjective phenomenon. One of the treatments for cancer patients is chemotherapy.

Purpose: The purpose of this study was to explore the experiences of nurses in implementing intravenous chemotherapy treatment programs in cancer patients.

Methods: This study uses a qualitative design with a phenomenological approach model to understand one's life experience and existing perceptions. The sampling technique used snow ball sampling. In this study, researchers will perform a snow ball sampling technique of participants who are at the Dr. Soedarso General Hospital. A total of ten nurses who work in the chemotherapy room participated.
\end{abstract}

Result: The perception of nurses in providing intravenous chemotherapy services as a form of carrying out their assigned duties and responsibilities apart from curiosity to carry out chemotherapy and their empathy for patients. Support from nurses in providing intravenous chemotherapy services is obtained from the family even though they are reminded to always be careful (protected), from the hospital, especially the improvement of infrastructure and related policies as well as support from colleagues and doctors. Obstacles for nurses in providing intravenous chemotherapy services arise from the capacity of nurses and specialists who are less trained, the inadequate reporting system between nurses during service changes including infrastructure such as PPE, room size and medicine.

Conclusion: Recommendations This study is expected to be used as a reference for future researchers related to the topic of nurse experiences that are still related to chemotherapy clients in cancer.

Keywords: Cancer, Chemotherapy, Nurse's Experience. 
Journal Of Nursing Practice

http://thejnp.org

ISSN: 2614-3488 (print); 2614-3496 (online)

Vol.5 No.1. October 2021. Page.168-175

\section{BACKGROUND}

Cancer is a disease that has become a public health problem in the world and in Indonesia. Every year, 24.6 million people worldwide suffer from cancer and 7.6 million of them die from cancer. If adequate control measures are not taken, by 2020 an estimated 10.3 million people will die from cancer every year. This incident will occur more rapidly in poor and developing countries International Union against Cancer (UICC) (2009). The World Health Organization (WHO) and UICC predict that there will be a 300 percent increase in cancer sufferers worldwide in 203).

In the Southeast Asian region cancer kills more than 1.1 million people every year. Based on the Hospital Information System (SIRS) in 2010 in Indonesia cancer became the cause of death Number 3. Based on Riskesdas (2014) the prevalence of cancer in Indonesia is 1.4 per 1,000 population and the prevalence in West Kalimantan is 0.8 per 1,000 population. According to The Centers for Disease Control and Prevention (CDC) (2013) in Indonesia cancer is the third leading cause of death after stroke and tuberculosis with an incidence of $6 \%$. Meanwhile breast cancer and cervical cancer are the highest types of cancer among other cancers in inpatients and outpatients in all hospitals in Indonesia with the proportion of Breast Cancer (28\%), Cervical Cancer (12.8\%), Leukemia (10.4\%), Lymphoma (8.3\%), Lung Cancer (7.8\%). In line with that empirical data also shows that deaths from cancer from year to year continue to increase. Meanwhile in West Kalimantan, especially RSUD dr. Soedarso Pontianak in 2013, data on the number of patients suffering from cancer reached 1559 people who were dominated by lung cancer and breast cancer. Of these, 155 of them underwent chemotherapy.

Based on the initial survey conducted at the Dr. Soedarso General Hospital, it was found that nurses who did chemotherapy initially wanted to seek different experiences outside of ordinary procedures, but they did not fully understand the side effects that could be caused by the implementation of chemotherapy itself. Motivated nurses will also get an added bonus for doing so.

\section{OBJECTIVE}

The general objective of this study is to explore the experiences of nurses in implementing intravenous chemotherapy treatment programs in cancer patients.

\section{METHODS}

This study used a qualitative research design with a phenomenological approach model, namely to understand one's life experience and existing perceptions. In qualitative phenomenological research tends to be believed to have very little sampling, usually 10 participants, with one principle that must be done, namely that all participants must experience the phenomenon and must be able to explain in words. The sampling technique uses snow ball sampling, namely by taking selected participants by previous participants. In this study, researchers will perform a snow ball sampling technique with a fixed participant scope. A total of 10 nurses who worked in the chemotherapy room participated in this study and met the criteria to be a participant, namely willing to participate in research and willing to recount perceptions, support, and obstacles that were felt and expressed with informed consent, working in the chemotherapy unit more than 2 years old, over 25 years old, able to communicate in Indonesian clearly and willing to recount his experiences. This research was conducted at the Dr. Soedarso General Hospital with the consideration of being a referral center hospital in West Kalimantan Province and treating many clients by undergoing chemotherapy. Interview activities are carried out in the nursing room. The research was conducted from March to June 2019 


\section{Journal Of Nursing Practice}

http://thejnp.org

ISSN: 2614-3488 (print); 2614-3496 (online)

Vol.5 No.1. October 2021. Page.168-175

The tools used to collect data were interview guides, field notes and an MP3 recorder. Previously, researchers tried to use an MP3 recorder recording device. The aim is to test the accuracy of the MP3 recorder that will be used and to validate the accuracy of the interview guide in extracting as much information as possible from the participants in accordance with the research objectives.

\section{RESULTS}

This study identified perceptions, supports and barriers, from the results of interviews with 10 nurses. the themes found in this study were about the perceptions obtained by the Task theme, about the support obtained from the theme of Health Services, Partners of Health Workers, Families, BPJS Services, and about the obstacles obtained from the theme of Facilities and Infrastructure, HR, service users.

\section{DISCUSSION}

The most educational backgrounds are Diploma III in nursing with a total of 8 people. Nurses in this hospital are still dominated by D3 education. As is the case in Indonesia in general, $80 \%$ of the nurses who work in hospitals have Diploma III education, while the rest are Diploma IV, Bachelor, Master, and even SPK. The length of time nurses working in chemotherapy range from 3 years to 15 years

The similarity of expressions of participants 1 to 10 is indicated by the line relationship from one participant to another. It was also found that participants 2 and 5 had the highest similarity of expressions with a value of 0.899 , then participant 7 . One of the similarities of the phrase "chemotherapy is only to prevent the spread of the disease suffered by the patient, so it does not help the healing of the term, so it only inhibits cells. so that the cancer cells do not expand, so it is not the meaning of chemo that the disease will disappear, it just inhibits it, helps inhibit the cells from expanding like that".

This research identifies perceptions, supports and obstacles, from the results of interviews with 10 nurses. The themes found in this study consisted of specific objectives that explored perceptions and obtained the theme of the task, special goal 2 regarding support was obtained by the theme of Health Services, Health Workers Partners, Family, Social Security Administering Body Services, and special objectives 3 regarding obstacles to obtain the theme of Facilities Infrastructure, Human Resources, Service Users.

According to CANO (2009) chemotherapy has a big risk to the officers who carry it out, the nurse is one who has a big role in its implementation. In the implementation of chemotherapy that is according to standards requires nurses who have competence in chemotherapy services. In this study, participants said that they carried out chemotherapy because it was a duty and responsibility at work even though the participants did not fully understand the proper procedure. This was also expressed by participant 10 in the following statement: "We help, indeed we have, there is no feeling tire

The feeling sub-theme consists of the sub-themes of anxiety, pleasure, just normal, at this time. The sub-themes of anxiety were expressed by the participants in the following statement: "Worried because all this time the common people know what chemotherapy drugs are for people who are seriously ill such as cancer, automatically the medicine is because the drug is especially strong, anxious, we already know the effect. there must be something like that for us". The sub-themes were happy to be expressed by the participants in the following statement: "happy, adding to experience and expanding knowledge, those of us who don't know will know."

The risk sub-theme is obtained from the sub-themes of places or facilities, medicine, personal protective equipment, nurse preparation in which there are sub-sub-themes of 


\section{Journal Of Nursing Practice}

http://thejnp.org

learning from seniors and never training, and the sub-theme of side effects to nurses. The sub-themes of the place or facility were expressed by the participants in the following statement: "The place of dissolution should not be there, but it is already from inadequate facilities, but now there is a separate room, so it doesn't involve us."

The sub-themes of medicine were expressed by the participants in the following statement "drug preparation, if the drug is complete we prepare the tools. If the equipment is incomplete, we cannot chemotherapy, one tool that is incomplete in the procedure, even though there is only one, we still cannot chemotherapy". The sub-themes of personal protective equipment were expressed by the participants in the following statement: "it is not optimal, for example it must be covered all the body, wear special shoes".

The sub-themes of side effects to nurses were expressed by the participants in the following statement "Because sometimes people usually refuse chemotherapy, because they are afraid of the risks, the risk is sometimes if people are pregnant they say the effect, so many avoid it. The sub-themes of nurse preparation were obtained from the sub-sub-themes of learning from seniors and never training. The sub-theme of learning from seniors was expressed by the participants in the following statement: "I learn from those who have participated in the training, so those who take part in the training convey it to friends who are here". The sub-theme of never training was expressed by the participants in the following statement: "Nothing, usually we immediately take action according to the procedure, most of which will explain later the doctor will explain".

The sub-theme of curiosity was expressed by the participants in the following statement: "People can why we can't. If people can, we have to be able, that's what makes me excited about going to chemotherapy. Even if we are in the hospital, if we are not appointed for chemotherapy where can we. Sub theme of the role of the nurse.

The sub-theme of the role of the nurse is obtained from the sub-themes of nursing care, job demands, empathy for patients, procedures, there is no oncology nurse and on call. The sub-theme, there was no oncology nurse, was expressed by the participants in the following statement: "If we do that, maybe we have to prepare personnel who do have certain personnel in chemotherapy installation, but we also lack here. The sub-themes of job demands were expressed by the participants in the following statement: "all nurses must know".

The sub-theme of vocations was expressed by the participants in the following statement, "We are already working according to our duties. We hope for incentives, we have been paid, have been paid and all the nurses have done that, there are no other rewards, sincerely, I hope the patient will recover quickly, we will help people in a sincere way ".

The sub-theme of procedure was expressed by the participants in the following statement: "So now the method is from the pharmacy, according to the procedure.

The sub-theme of empathy for the patient was expressed by the participants in the following statement: "If I urge you, especially if you are like patients, when it is in the final stage, some maggots come out".

The ascep sub-theme was obtained from the sub-sub-theme, assess the readiness, during the process and evaluate the side effects to the patient. The sub-sub-theme of the preparatory study was expressed by the participants in the following statement: "The patient is admitted to the hospital, comes, checks the status of the blood pressure measurement, the temperature reports to the doctor, this is a patient who wants surgery, chemotherapy continues to be like this, there is no fever. Then for chemotherapy drugs before, the patient is a consul with the doctor, right, that means he's already taking chemotherapy drugs ".

The sub-themes during the process were expressed by the participants in the following statement: "If the morning is half an hour, observe half an hour, another half hour, because 
Journal Of Nursing Practice

http://thejnp.org

ISSN: 2614-3488 (print); 2614-3496 (online)

Vol.5 No.1. October 2021. Page.168-175

I am there my patient will be there every half hour, after half an hour there is no reaction, then one hour we observe again.

The sub-theme of the evaluation of side effects to the patient was expressed by the participant in the following statement "Maybe at the first insertion he had vomiting, there might be nausea. So the nausea is just a little bit like that, but we still evaluate the patient, because if it's not evaluated it's afraid the patient will suddenly vomit or what about it, I'm sorry. "

Based on the participant's experience, it was found that the nurses' perceptions of implementing chemotherapy because of their duties. Participants mentioned four things that underlie this because of their duties, including: the role of the nurse, being at risk, wanting to know, and feeling. The relationship between sub-themes (nodes) in the task theme and participants (sources). The sub-themes that were most discussed by the participants in order were feelings, the role of nurses, risks, and curiosity.

Experience is a term that is loaded with meaning and meaning. Among them we find from real life through events or incidents, real life is in stark contrast to ideals, imagination. Other senses refers to knowledge, skills or techniques that result from experience, or to cumulative additions and have residual experiences. All information about various things reaches us through the senses. To understand experience, we must know how experience is formed. Experience is formed from perception and sensory through the sensese (Erlich, 2018).

Nurses' perceptions in implementing chemotherapy programs are part of the experience. Based on the results of interviews that have been conducted in the study, it was obtained the participants' perceptions of chemotherapy as providing drugs for malignant tumors or so-called cancer patients which function to inhibit cancer cells. Chemotherapy is a cancer treatment therapy using chemicals. It also has an important role in cancer therapy. Chemotherapy is used for healing and improves patient survival for longer. This therapy is used because it can selectively kill cancer cells beyond normal cells (Ignatavicius \& Workman, 2010).

The facts that occur in the field, according to the experience of nurses in implementing chemotherapy, are due to the task even though the participants said they did not understand the proper procedure but were still carried out. In carrying out their duties as nurses, participants feel anxious, this is because the participants are doing chemotherapy without any special preparation in the form of training and lack of knowledge. Participants also felt anxious considering the risks that could occur to nurses who administer chemotherapy. Participants also stated that doing chemotherapy is a risky task because the place or facilities are inadequate or personal protective equipment does not meet standards.

Some nurses also carry out chemotherapy using personal protective equipment that does not meet these standards experiencing side effects or exposure to these drugs to nurses such as burning on the skin, dry throat feeling. This shows that the implementation of chemotherapy they do is not in accordance with the theory according to Hinkle \& Cheever (2014) and CANO (2009), namely: for safety in chemotherapy treatment for service providers/ nurses/ other medical personnel when doing chemotherapy, they should use safety equipment that is has been established to prevent exposure to nurses as well as implement competency-based education, training on safety procedures during chemotherapy.

Participants said that in the task of providing chemotherapy, nurses must evaluate the side effects that occur in patients. According to participants, the side effects that often occur in patients are hair loss, nausea, vomiting, and the patient also looks tired. This is in accordance with the research of Aslam et al (2014) which states that the most common side effects are weakness, fatigue, nausea, hair loss and vomiting with an incidence of more than 


\section{Journal Of Nursing Practice}

http://thejnp.org

$70 \%$. Other notable side effects include mouth sores, dry mouth and numbness. Conversely diarrhea, stomach cramps and memory disturbances are rare side effects. Some of the other side effects reported by some patients were increased temperature, constipation, mood swings and weight loss (Aslam, 2014).

Research conducted by Waheida et al (2015) revealed that nurses did not comply with the recommended safety regulations. This is due to an increase in workload, lack of knowledge and a lack of equipment and facility studies. This shows that there are not enough steps taken by nurses to treat cytotoxic drugs that have a negative impact on their health (Waheida, 2015).

Based on the results of the interview, the participants said that related to the placement of consumable devices, separations had been made between chemotherapy consumables and devices for patients in general to prevent contamination from the effects of chemotherapy. This is consistent with the theoretical review of the prevention of exposure through inhalation and direct contact according to Hinkle \& Cheever (2014), namely a closed system, puncture and leak-proof container labeled "dangerous: contaminated chemotherapy linen", referenced/ marked, put in a container and managed. in the central dirty laundry room for outpatient settings, referenced/ marked, put in containers and managed in patient rooms and / or dirty laundry rooms for inpatient settings Preparation of chemotherapy equipment namely syringes, tubes, empty bottles, clothes and gloves hands should be disposed of in a closed system, puncture and leak-proof container labeled "danger of chemotherapy waste contaminated."

Based on the results of interviews that have been carried out in the study, participants said that currently the implementation of chemotherapy is in accordance with standard procedures set by the hospital. This is consistent with the theoretical review of Hinkle \& Cheever (2014), which states that in implementing improved quality safe chemotherapy treatment programs which include: standard operating policies and procedures for handling, preparation and disposal of chemotherapy, handling and disposal of spills during chemotherapy, treatment and disposal of blood and body fluids and contaminated material from patients undergoing chemotherapy.

One of the reasons the participants took chemotherapy services was because they were curious and sought additional experience outside of ordinary procedures. In doing chemotherapy, initially the nurse did not have much knowledge about chemotherapy so that it increased the anxiety of the nurse. However, in the end, the participants stated that now the anxiety was much reduced due to experience and training in implementing chemotherapy. The participant's statement was also supported by research conducted by Veritya (2008) which concluded that almost all nurses said they were afraid and anxious when initially working with chemotherapy. Then they become more confident with experience, if supported by knowledge and follow chemotherapy education (Verity, 2019).

In a study conducted by Kassa \& Kassa (2014) it was found that nurses received the same salary as nurses who worked in other units while the risk burden that threatened life during chemotherapy was higher. One other statement from the participants initially wanted to join the oncology unit to find out how to administer chemotherapy and other pain management measures. After hearing and reading about the side effects of cancer therapy on health workers, she tried to avoid going to the ward, especially if her schedule was for chemotherapy (Ali et al, 2012)

\section{CONCLUSION}

The perception of nurses in providing intravenous chemotherapy services as a form of carrying out their assigned duties and responsibilities apart from curiosity to carry out 


\section{Journal Of Nursing Practice}

http://thejnp.org

ISSN: 2614-3488 (print); 2614-3496 (online)

Vol.5 No.1. October 2021. Page.168-175

chemotherapy and their empathy for patients. Support from nurses in providing intravenous chemotherapy services is obtained from the family even though they are reminded to always be careful, from the hospital, especially the improvement of infrastructure and related policies as well as support from colleagues and doctors. The government, in this case the role of social security administering bodies, is also expressed as supporting the implementation of the provision of chemotherapy services for patients. Obstacles for nurses in providing intravenous chemotherapy services arise from the capacity of nurses and specialists who are less trained, the inadequate reporting system between nurses during service changes, including facilities and infrastructure. such as PPE, room size and medicine. The patient's family can also hamper services because they are worried about the work for the nurse. Patients and families become obstacles when they do not understand the side effects of chemotherapy, lack of cooperation related to bringing young children to chemotherapy rooms and especially the physical condition of patients who are not ready for chemotherapy.

Hopefully this research recommendation can be used as a reference for future researchers related to the topic of nurse experiences that are still related to or related to chemotherapy clients in cancer. This research can also be the main capital for future researchers to continue quantitative research related to chemotherapy.

\section{ACKNOWLEDGMENTS}

Thank you to the nurse from Dr. Soedarso General Hospital.

\section{CONFLICTS OF INTEREST}

There was no conflict of interest during this research.

\section{REFERENCES}

International Congress and Convention Association. 2018 Country \& City Rankings. Int Congr Conv Assoc [Internet]. 2018;85. Available from: https://www.iccaworld.org/newsarchives/archivedetails.cfm?id=1100291

National Cancer Society. Children with Cancer: A Guide for Parents. Natl Cancer Inst. 2015;1-79.

Keperawatan J, Tanjungkarang PK. PENDERITA KANKER.

Iseki K. II. Epidemiology. Nihon Naika Gakkai Zasshi [Internet]. 2010;96(5):869-74. Available from: https://www.cdc.gov/traumaticbraininjury/pdf/blue_book

Creswell JW. Research Design: Qualitative, Quantitative, and Mixed Methods Approaches. 2009;35(2):2-4.

Kemenkes RI. Info Sehat untuk Semua: Kanker Pembunuh Papan Atas. Mediakom. 2015. $27 \mathrm{p}$.

Hartzell R, Hues B, Karrei I, Lejambe V, Mercer L, Oliver J, et al. Standards and Competencies for Cancer Chemotherapy Nursing Practice.

Erlich S. Experience--What is it? 2018;(December).

Aslam MS, Naveed S, Ahmed A, Abbas Z, Gull I, Athar MA. Side Effects of Chemotherapy in Cancer Patients and Evaluation of Patients Opinion about Starvation Based Differential Chemotherapy. 2014;(January).

Waheida SM, Abd-elgaffar SI, Abd G, Atia F. Evaluation of Handling Practices of Oncology Nurses during Chemotherapy Preparation and Administration in Menoufia Oncology Hospital. 2015;2(3):107-19.

Verity R, Wiseman T, Ream E, Teasdale E. Exploring the work of nurses who administer 


\section{Journal Of Nursing Practice}

http://thejnp.org

ISSN: 2614-3488 (print); 2614-3496 (online)

Vol.5 No.1. October 2021. Page.168-175

chemotherapy. 2008;(March 2019).

Ali TS, Khan N, Zulfiqar K, Khowaja A, Ali TS. Assessment of knowledge, skill and attitude of oncology nurses in chemotherapy administration in tertiary hospital Pakistan . nurses in chemotherapy administration in tertiary. 2012;2(June):97-103. 